\title{
ARGILOTERAPIA: TRATAMENTO FACIAL COM ARGILA VERMELHA EM PELES MADURAS
}

\section{ARTIGO ORIGINAL}

RIBEIRO, Gabrielle de Oliveira ${ }^{1}$

SILVA, Carlena Sinara Martins da ${ }^{2}$

RIBEIRO, Gabrielle de Oliveira. SILVA, Carlena Sinara Martins da. Argiloterapia: Tratamento facial com argila vermelha em peles maduras. Revista Científica Multidisciplinar Núcleo do Conhecimento. Ano 05, Ed. 11, Vol. 06, pp. 155-165. Novembro de 2020. ISSN: 2448-0959, Link de acesso:https://www.nucleodoconhecimento.com.br/saude/peles-maduras

\section{RESUMO}

Há muito tempo a argila vermelha vem sendo usada para tratamentos estéticos em forma de máscara facial, em sua formulação ela é rica em ferro e cobre que auxiliam na respiração celular e tem como característica ser extremamente suave apresentando como resultado uma pele revitalizada, hidratada, sem oleosidade e macia, consequentemente com uma aparência mais jovem e linhas de expressões suavizadas. Desse modo, o presente trabalho tem a finalidade de mostrar em relato de caso, as aplicações feitas com a máscara facial de argila vermelha em forma pastosa na área facial higienizada, deixada agir por 20 a 25 minutos e retirada com agua morna. Os resultados foram coletados por meio de fotografias e questionário aplicado, os efeitos da argila vermelha em peles maduras, na região facial, visando as

\footnotetext{
${ }^{1}$ Estudante.
}

${ }^{2}$ Orientadora. Doutorado em andamento em Rede De Biodiversidade E Biotecnologia Da Amazônia Legal - Bionorte. Mestrado em Biocências. Especialização em Farmácia Estética. Especialização em Farmacologia Clínica. Graduação em Bacharelado Em Farmácia. 
linhas de expressão, o seu modo de uso correto e o tempo para que se tenha um resultado satisfatório. Portanto, fornecer as informações necessárias para que outras pessoas conheçam os benefícios da argila vermelha, será um grande avanço e incentivo a população procurar em forma natural de tratar as linhas de expressão, possibilitando o uso da máscara facial e melhorar a autoestima do mesmo.

Palavras-Chave: Relato de caso, argila vermelha, linhas de expressão, máscara facial, peles maduras.

\section{INTRODUÇÃO}

As argilas são materiais terrosos, com partículas cristalinas e granulação fina, composta por: ferro, cobre, alumínio, silício, cálcio, titânio, magnésio e outros que apresentam benefícios buscados no meio estético. A argila vermelha tem como função de estimular a produção de colágeno, aumentar a elasticidade da pele e melhorar as marcas de linhas de expressões, tem um alto poder de absorção eliminando qualquer deposito de sujeira no rosto, reduz a oleosidade e outras impurezas deixando a pele com aspecto de macia e aveludada (SANTOS, 1989; VIEIRA et al., 2003; BONOTTO, 2009).

Segundo Ribeiro (2010), a argila vermelha é enriquecida com oxido de ferro contendo propriedades tensoras, podendo ser usada como máscara facial em tratamentos estéticos, tendo como proposta tratar pacientes com peles maduras, visando áreas como linhas de expressão, manchas, clareamento da pele, estimulação de colágeno dentre outros benefícios. Zague (2007), afirma que Cleópatra, conhecida como a antiga deusa egípcia tinha como hábito cuidar da beleza utilizando argilas como máscaras faciais para a conservação da pele. Há relatos que foi Pompeia, quem desenvolveu a máscara facial para prevenir a pele contra a ação ultravioleta e agressões do dia a dia, fazendo com que sua pele ficasse com uma aparência de delicadeza e cuidado.

Atualmente mesmo com os avanços tecnológicos ainda há buscas pelo tratamento natural, visando os princípios ativos naturais que estão presentes nas formulações 
que contribuem com os procedimentos estéticos e pelo motivo de não apresentar tantas reações no rosto e agressões como ressecamento da pele. Contudo, o objetivo é relatar um caso de avaliação dos efeitos da argila vermelha em peles maduras especificamente em linhas de expressão, qualificar a argila vermelha como um produto plausível em tratamentos estéticos e ter um resultado satisfatório também na autoestima do paciente, visto que a marca de linhas de expressão tornasse um incomodo e um motivo para que as pessoas procurem cada vez mais os procedimentos estéticos.

\section{RELATO DE CASO}

O trabalho foi realizado no município de Santarém - PA, como relato de caso, tomando-se como referência a norma operacional CNS 001 de 2013 e a Carta Circular 166/2018 da CONEP. Com pacientes do sexo feminino e masculino, com mais de 40 anos, sadios, sem doenças crônicas ou comodidades, foi aplicado a argila vermelha como máscara facial, conferindo o tempo de 20 a 25 minutos buscando resultados em linhas de expressão.

O procedimento baseou-se em sessões de aplicações da argila vermelha, a máscara facial feita do pó da argila e agua morna, foi aplicada no rosto do paciente com auxílio de um pincel cobrindo toda a região facial com o produto em forma de argila pastosa, conferindo um tempo de 20 a 25 minutos, retirando-a do rosto com agua morna.

A aplicação do procedimento estético realizou-se em uma sala especifica, na Clínica de Estética T R F DE ANDRADE, dessa forma evitou-se todo tipo de constrangimentos entre os pacientes, também não ocorreu interferências na rotina da clínica de estética pelo motivo da sala ser reservada apenas para este tipo de aplicação e o espaço foi concedido em horário não comercial, reservando assim a confidencialidade do paciente, além de está apta ao desenvolvimento da pesquisa e para atender eventuais problemas dela resultantes conforme recomenda a Norma Operacional do CNS 001/2013. 
O deslocamento dos participantes não teve custo algum aos mesmos, sendo pago pela pesquisadora todo custo necessário para transporte como por exemplo: uber. Por meio de respeito a todas as normas de biossegurança, como: Uso de máscara e luvas, também com material esterilizado para evitar qualquer tipo de contaminação.

Dessa forma, em todas as etapas, foi realizado o registro por meio de fotografia no paciente 1, homem e na paciente 2, mulher (figuras 1, 2 e 3), após a terceira aplicação (figura 2) os pacientes já observavam melhoras nas linhas de expressões, comprovando a eficácia da mesma, na 6 aplicação (figura 3) nota-se uma grande diferença para a figura 1, observa-se que as linhas de expressões se encontram mais suavizadas dando uma aparência mais jovem.

Figura 1 - Área facial antes das aplicações da máscara facial, observa-se em paciente 1 , homem e paciente 2, mulher, as marcas visíveis de linhas de expressões localizadas no canto dos olhos.
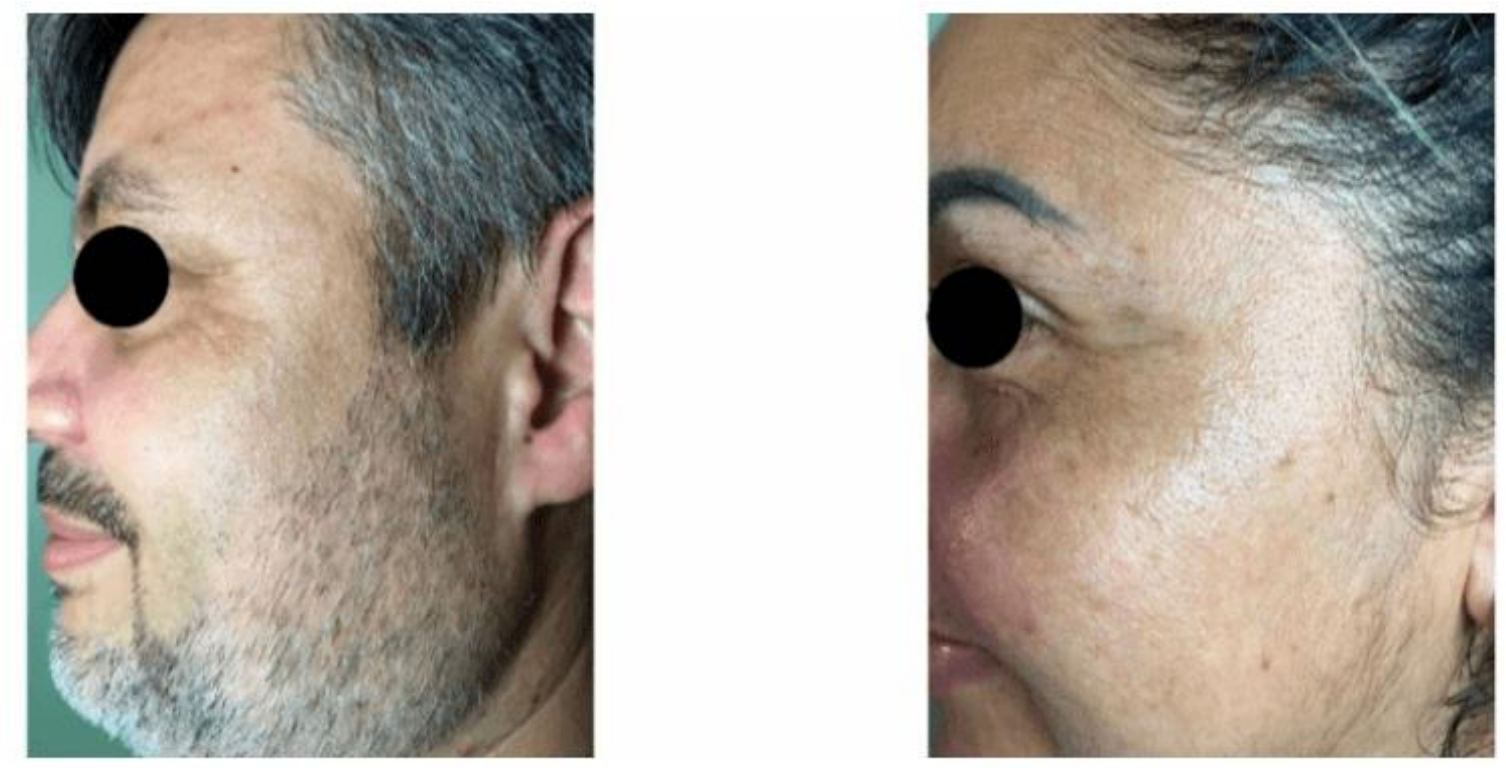

Fonte: arquivo pessoal

Figura 2 - Terceira aplicação de argila vermelha nos pacientes, nota-se no paciente 1, homem, que na área principal de aplicação já apresenta um resultado desde a figura 1, pode-se afirmar que houve um resultado de minimização na área do canto dos olhos. Na paciente 2, mulher, notando no canto dos olhos onde as linhas de 
expressões se destacam mais como vemos na figura 1, já é possível enxergar uma diferença na marcação de linhas de expressões. Tanto paciente 1 como paciente 2 obtiveram um resultado esperado com a argila vermelha.
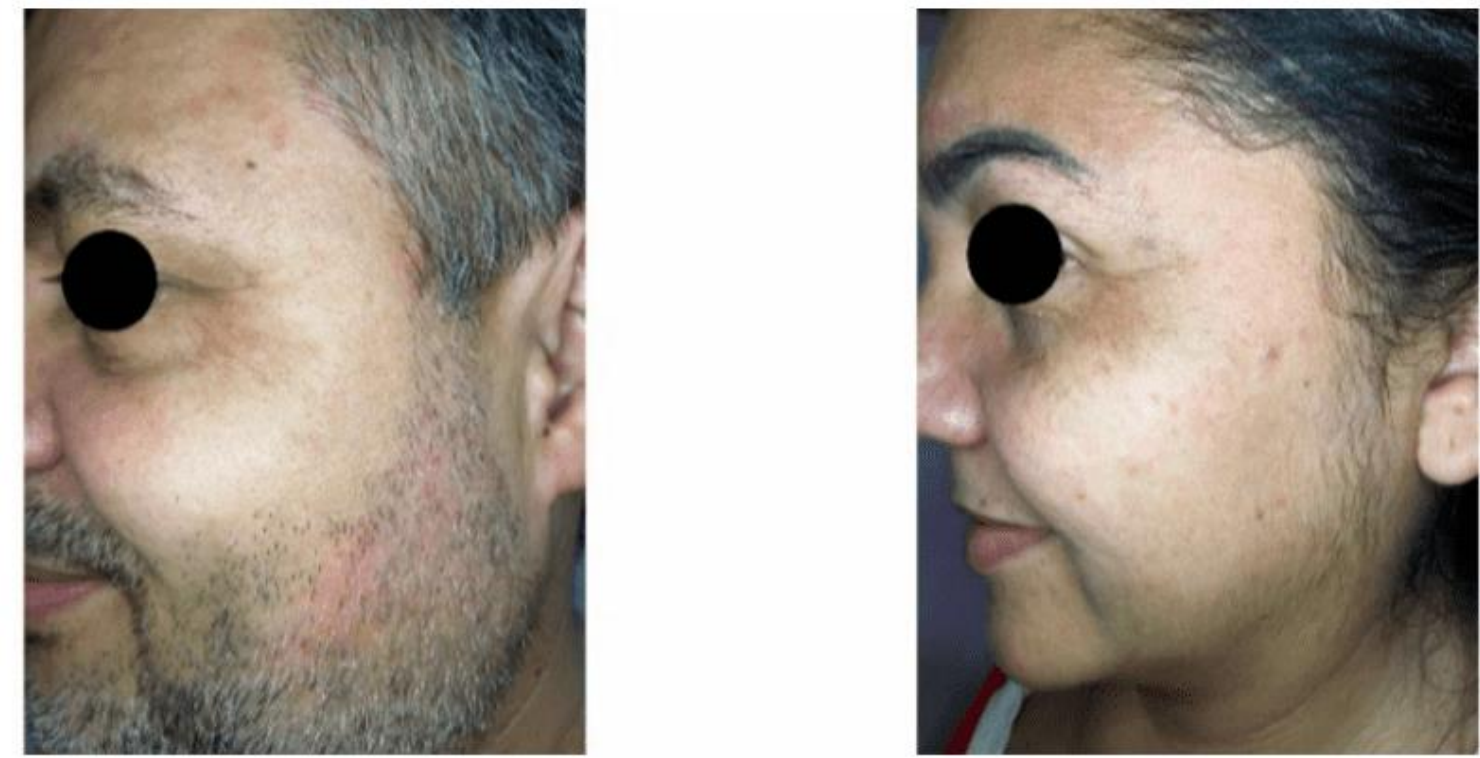

Fonte: arquivo pessoal

Figura 3 - Sexta aplicação de argila vermelha e última sessão, nota-se um resultado satisfatório. Paciente 1, homem, observa-se a minimização nas linhas de expressões não estando mais visível, aparentando uma pele mais jovem e menos cansada. Paciente 2, mulher, podemos ver um resultado satisfatório na área desejada, com a minimização total de linhas de expressões aparentando uma pele mais jovem sem resquícios de marcas, sendo assim, pode-se comprovar que a argila vermelha age sobre peles maduras exclusivamente em linhas de expressões. 

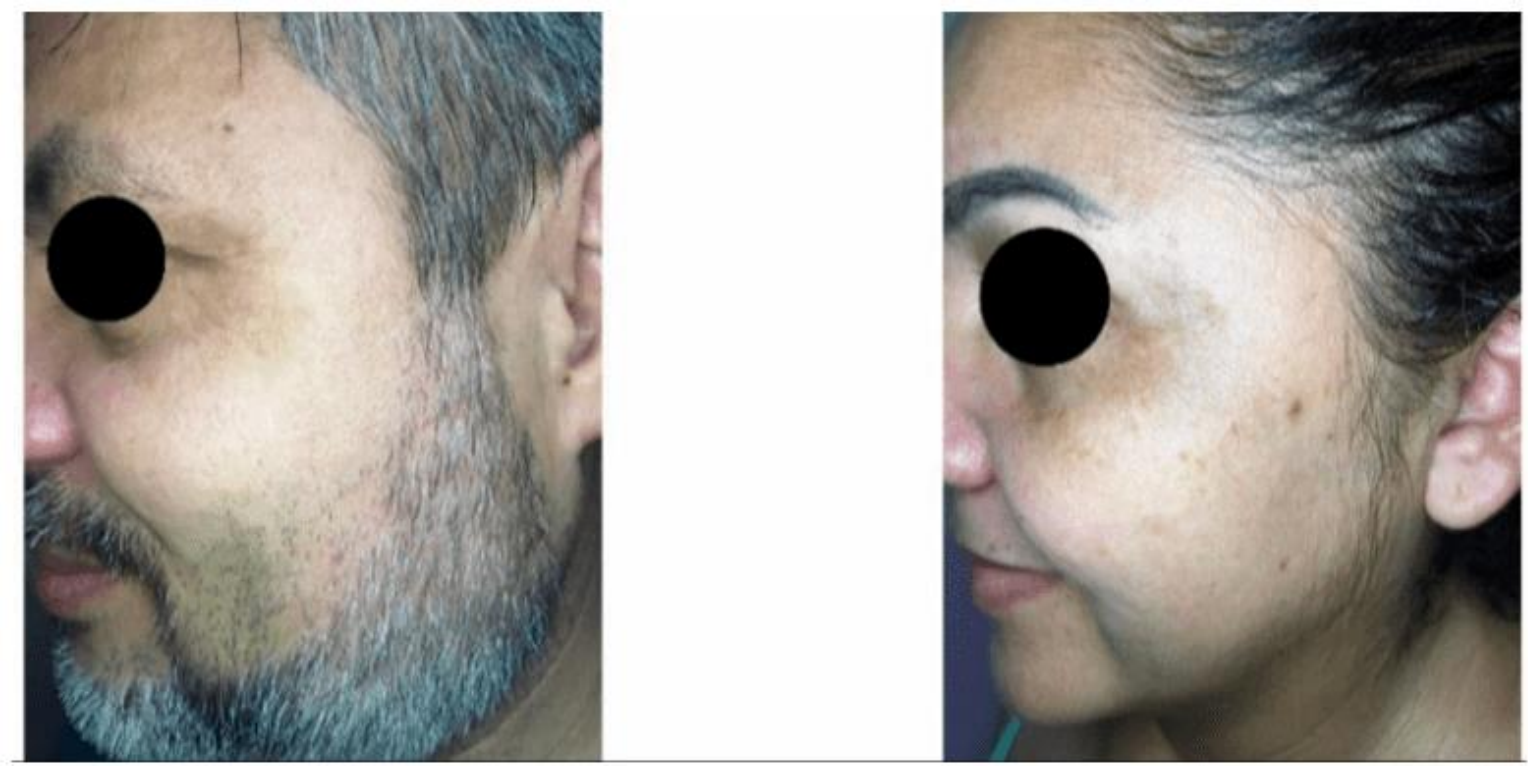

Fonte: arquivo pessoal

Observamos nas fotografias (Figuras 1, 2 e 3), a minimização das linhas de expressões na área do canto dos olhos.

Paciente 1, homem, na figura 1 podemos observar a área facial com marcas bem visíveis de linhas de expressões, na figura 2, terceira aplicação, vemos que as linhas de expressões estão mais suavizadas, já podendo dizer que o tratamento está tendo o objetivo alcançado, por fim na figura 3, sexta aplicação, é possível notar uma diferença significativa na área desejada, aparentando sem linhas de expressões e bem mais jovem desde a figura 1, conclui-se que as aplicações tiveram eficácia e que pode ser usada para tratamento facial.

Paciente 2, mulher, observamos que as linhas de expressões são bem notáveis deixando a aparência da pele cansada e envelhecida. Com a argila vermelha que é especifica para peles maduras, observamos na figura 2 já uma diferença enquanto as linhas de expressão, já trazendo um aspecto de mais jovem e menos grotesca, na figura 3, relata-se a sexta e última aplicação, onde podemos dizer que a argila vermelha agiu sobre as linhas de expressão deixando a pele sem marcas e mais jovem. 
Contudo, na primeira fotografia (figura 1) observa-se expressões faciais marcantes, pele com aparência envelhecida, após a primeira aplicação da máscara facial apresentou-se mais suavizada pelo motivo da argila vermelha relaxar a área e começar a agir nos pontos específicos quando absorvidas pela pele (DORNELLAS e MARTINS, 2013).

$\mathrm{Na}$ segunda fotografia (figura 2), observa-se as linhas de expressões mais suavizadas, menos marcada na área do canto dos olhos ajudando na uniformização da pele aparentando mais jovem como dizia (DORNELLAS e MARTINS, 2013) que a argila vermelha possui ação suavizante e rejuvenescedora.

$\mathrm{Na}$ terceira fotografia (figura 3) conclui-se que a argila vermelha age sobre a pele especificamente nas linhas de expressões comprovando a eficácia da argila vermelha para tratamento estético, não é mais possível ver rugas dinâmicas no canto dos olhos dos pacientes como condiz na figura 1.

Tabela 1: Satisfação dos pacientes após a finalização do protocolo com argila vermelha

\begin{tabular}{|l|c|l|}
\hline Perguntas & Resposta Paciente 1 & Respostas Paciente 2 \\
\hline $\begin{array}{l}\text { Houve melhora nas linhas de } \\
\text { expressão? }\end{array}$ & Sim Sim \\
\hline $\begin{array}{l}\text { Sentiu a pele mais suavizada? } \\
\text { Como você qualifica as linhas de } \\
\text { expressões na área dos olhos depois } \\
\text { das aplicações da máscara facial feita } \\
\text { de argila vermelha? }\end{array}$ & Ótima & \begin{tabular}{l} 
Sim \\
\hline $\begin{array}{l}\text { Otratamanto causou alguma } \\
\text { mudança na sua vida? }\end{array}$
\end{tabular} \\
\hline $\begin{array}{l}\text { Em quais aspectos houve mudança? } \\
\text { tram }\end{array}$ & Sim & \\
\hline
\end{tabular}




\begin{tabular}{l|c|c|}
\hline $\begin{array}{l}\text { Sofreu alguma reação alérgica } \\
\text { durante ou após as aplicações ? }\end{array}$ & Não \\
\hline $\begin{array}{l}\text { Faria novamente o tratamento com } \\
\text { argila vermelha? }\end{array}$ & Sim & Sim \\
\hline $\begin{array}{l}\text { Pagaria pelo tratamento? } \\
\text { Indicaria para alguém este } \\
\text { tratamento? }\end{array}$ & Sim & Sim \\
\hline
\end{tabular}

Fonte: Formulário de satisfação do paciente

No questionário aplicado o paciente 1 retrata a sua satisfação com o tratamento, relata que que houve diferença em sua pele, além de melhora nas linhas de expressões e que faria novamente assim como indicaria o tratamento. A paciente 2 retrata que houve melhora na autoestima e observou a diferença nas linhas de expressões após as aplicações de argila vermelha e retratou que faria novamente assim como indicaria a outra pessoa o tratamento. O resultado obtido é de grande relevância para a sociedade, pois, apresentou resultados nítidos nos pacientes como a minimização as linhas de expressões aparentando uma pele mais jovem, rejuvenescida e hidratada. A argila vermelha é um produto natural com um custo financeiro muito baixo, podendo ser usado por todas as classes sociais.

\section{DISCUSSÃO}

Os resultados do estudo relacionado a estética facial e uso de argila têm demonstrado que a argila traz grandes benefícios para a pele, principalmente na face. De acordo com Limas (2010), a argila pode ser utilizada como tratamento estético objetivando um tratamento que visa uma pele mais bonita e saudável de uma forma natural, sem a utilização de cosméticos e produtos químicos.

Sampaio (2008) afirma que a argila vermelha tem eficácia pelo motivo de seus elementos minerais que auxiliam na vibração celular da pele trazendo benefícios rejuvenescedores a pele e deixando a aparência de mais jovem. $O$ autor supracitado (2015), em seu estudo sobre uso da argila e o tratamento estético facial, evidenciou 
ainda que a argila tem efeitos de suavizante. Logo, nas linhas de expressão é possível o uso da argila vermelha para em busca de resultados na minimização da mesma e aparentar uma pele mais jovem.

Os pesquisadores Dornellas e Martins (2013), citam que as argilas têm suas características de acordo com suas cores, logo, a argila vermelha por ser rica em ferro-férrico, possui uma ação regeneradora afim de suavizar rugas dinâmicas e trazer a que busca um resultado de pele mais jovem e revigorada. A argila vermelha possui em sua composição o poder de regeneração e calmante trazendo consigo o retardo no envelhecimento, como vemos no trabalho o resultado nas linhas de expressões foram visíveis a ponto de confirmar que a argila vermelha age sobre as linhas de expressão regenerando e trazendo a aparência de mais jovem para o paciente (MASCKIEWIC, 2014).

Lamaita (2014), mostrou em seu estudo que a argila possui em suas propriedades a forma como irá minimizar as linhas de expressões sobre a pele, sendo absorvida em meio aquoso facilitando a entrada de seus elementos e então trazendo o resultado esperado pelo paciente.

Segundo Dornellas e Martins (2013), a argila apresenta propriedades importantes, devido às trocas iônicas que ocorrem entre seus elétrons livres (íons Ferro) é recomendável que seja aplicada de forma aquosa para a facilitação da absorção na pele. Nela possui propriedade que é fundamental em tratamentos estéticos especificamente em linhas de expressões. Tendo um resultado satisfatório como visto no decorrer do trabalho. Ainda de acordo com Dornellas e Martins (2013) a argila vermelha regula a pele e consequentemente renova a parte celular, também é revitalizante, nutritiva e hidratante, elimina os radicais livres e com isso, retarda o envelhecimento e auxilia na suavização de marcas de expressão.

Sposito et al. (2003) afirma que a argila em contato com a água tem a sua entrada facilitada na pele, podendo então ser usada como máscara facial e sendo administrada com o tempo necessário é possível obter um resultado. Neste relato de caso a argila vermelha foi usada como máscara facial pastosa feita a mistura com 
água, sendo assim, teve a entrada facilitada na célula epiderme e derme, possibilitando um resultado satisfatório na área desejada pelos pacientes.

Portanto um dos principais elementos da argila vermelha é o ferro sendo um dos principais presentes na argila, pelo motivo do seu papel de respiração celular e rejuvenescedora, por este motivo neste trabalho obtivemos resultados visíveis tanto no paciente 1 como na paciente 2, conforme nos estudos de (MEDEIROS, 2007).

Verifica-se nos autores estudados que os efeitos da argila estão diretamente associados ao tratamento da linha de expressão, dessa forma, com a aplicação correta pode-se obter resultados excelentes, como foi feito neste relato de caso. A leitura dos autores pesquisados nos leva a concluir que, apesar de reconhecer as propriedades da argila, torna-se fundamental aplicar a argila certa na pele para melhor propor a aplicação correta do produto e administrar o tratamento adequado.

\section{CONSIDERAÇÕES FINAIS}

Considerando o conjunto de artigos que caracterizaram o tema do uso da argila vermelha para procedimentos estéticos faciais, foi possível avaliar que a mesma apresenta eficácia nas suas aplicações, pode-se afirmar que para tratamento estético é eficaz. No ramo estético pode alcançar resultados satisfatórios em seus procedimentos associando as aplicações com o uso correto da argila. A finalidade deste relato de caso foi mostrar a ação da argila no paciente 1 e paciente 2 e afirmar por meio de aplicações das máscaras faciais, que a argila possui a eficácia pelo motivo de suas funções e minerais presentes, podendo trazer resultados satisfatórios a quem faz o uso da mesma, pois pode-se utilizar-lhe para prevenir o envelhecimento e consequentemente repor a luminosidade da pele. Nos resultados deste relato de caso foi possível ver no paciente 1 a resposta significativa do tratamento, pois, a minimização nas linhas de expressão ocorreu consideravelmente trazendo ao paciente uma aparência mais jovem, na paciente 2 também foi possível o relato de resultado satisfatório com o uso da máscara, trazendo para a mulher uma melhora na autoestima e tendo a resposta bem positiva pelo tratamento. A argila vermelha tem sido cada vez mais usada na área da estética devida suas inúmeras propriedades e 
funções, sendo utilizadas para tratamentos de pele. Para que o uso dessas máscaras seja valorizado, faz-se necessário o domínio de informações básicas sobre o produto a serem utilizado e os procedimentos básicos que os acompanham. Portanto, a aplicação da máscara facial evidenciou por apresentar resultados na minimização de linha de expressão, além de melhorar a saúde geral da pele.

\section{REFERÊNCIAS}

BONOTTO, D. M. Geoquímica do Uranio Aplicada as Aguas Minerais. São Paulo: UNESP, 2009.

DORNELLAS, E.; MARTINS, S. 0 poder das argilas: geoterapia. Disponível em: $<$ http://www.casaclean.com.br/downloads/OpoderdasArgilas.pdf> Acesso em: 02 nov.2020.

LAMAITA, G. Argiloterapia: Menos toxinas e mais vitalidade. Disponível em: http://equilibriopleno.blogspot.com/2009_06_01_archive.html>. Acesso em: 02 nov. 2020.

LIMAS, JAQUELINE R. A Argiloteraía: uma nova alternativa para tratamentos esteticos. 2010. Universidade do Vale do Itajaí. Disponível<www.siaibib01.univali.br/pdf>. Acessado em: 21/07/2020.

MEDEIRO, Sandra; LANZA, Marcos. Modo de ação das argilas na pele, quando aplicadas em tratamentos estéticos.

MASCKIEWIC, E. Argila. Revista Bel Col, Ed.55, jan. 2014.

RIBEIRO, Claudio de Jesus. Cosmetologia aplicada a dermoestetica. 2. ed. São Paulo: Phamabooks, 2010.

SPOSITO, G.; ZABEL, A. Cadernos de Ciência \& Tecnologia, Brasília, v. 18. 20, n. 3, p. 391-411, set./dez. 2003. 
SAMPAIO, J. A. et al. Manganês: comunicação técnica elaborada para o livro rochas minerais industriais: usos e especificações. parte 2 - rochas e minerais industriais: usos e especificações. Centro de Tecnologia Mineral. Ministério da Ciência e Tecnologia. Rio de Janeiro, 2008.

SAMPAIO, J. A. et al. Manganês: comunicação técnica elaborada para o livro rochas minerais industriais: usos e especificações. Parte 2 - rochas e minerais industriais: usos e especificações. Centro de Tecnologia. Rio de Janeiro, pág. 633-648. Cap. 28, 2008. Disponível em: http://simineral.org.br/arquivos/MangansCETEM.pdf acesso em: 10 marc. 2020.

SANTOS, P de S. Ciência e Tecnologia de Argilas. 2. ed., São Paulo: Edgar blucher, 1989.

VIEIRA, C.M.F; MONTEIRO, S.N. Influencia da temperatura de queima na microestrutura de argilas de Campos dos Goytacazes-RJ. Cerâmica, v 49, p. 6-10, 2003.

ZAGUE, V et al. Argilas: natureza das máscaras faciais. Cosmetics\&Toiletries, v. 19,

Enviado: Novembro, 2020.

Aprovado: Novembro, 2020. 